\title{
Switching from systemic steroids to ciclesonide restores the hypothalamic pituitary-adrenal axis
}

\author{
Jerzy Marczak ${ }^{1}$ Maciej Ciebiada², Paweł Górski ${ }^{1}$
}

'Department of Pneumonology and Allergy, Medical University of Lodz, Poland Head of Department: Prof. Paweł Górski MD, PhD

2Department of General and Oncological Pneumonology, Medical University of Lodz, Poland

Head of Department: Prof. Adam Antczak MD, PhD

Postep Derm Alergol 2014; XXXI, 2: 59-64

DOI: $10.5114 /$ pdia.2014.40924

\begin{abstract}
Introduction: Treatment of difficult asthma with oral corticosteroids (OCS) may suppress the hypothalamic-pituitary-adrenal axis.

Aim: In this study we have checked if the substitution of OCS with very high doses of ciclesonide may restore the adrenal function without losing the control of the disease.

Material and methods: In 5 patients with difficult, uncontrolled asthma despite treatment with OCS, inhaled and systemic glucocorticosteroids were replaced with very high doses of ciclesonide (1600-2400 $\mathrm{\mu g} / \mathrm{day})$. The symptoms of asthma and the lung function were assessed at baseline and on the $28^{\text {th }}, 56^{\text {th }}$ and $70^{\text {th }}$ day of treatment, whereas the levels of cortisol and adrenocorticotropic hormone (ACTH) in the morning were measured at baseline and on the $28^{\text {th }}$ and the $56^{\text {th }}$ day of treatment.

Results: In all patients, the control of asthma symptoms, measured with Asthma Control Test questionnaire, improved from the mean score of 9.4 to 19.8 in 70 days. In 4 subjects force expiratory volume in $1 \mathrm{~s}$ improved gradually through the entire study reaching a mean improvement of $585 \mathrm{ml}$ in 70 days. The ACTH levels were normalized in 3 patients after 28 days of observation and in all patients after 56 days. The cortisol level was normalized in 4 patients after 28 days and in another subject after 56 days of treatment with ciclesonide.

Conclusions: Switching from prednisone to very high doses of ciclesonide normalized the hypothalamic-pituitary adrenal axis function and also improved the disease control and the lung function in these 5 patients with difficult asthma.
\end{abstract}

Key words: ciclesonide, corticosteroids, severe asthma, therapy, adrenal function.

\section{Introduction}

The treatment of chronic airway inflammation in asthma requires a systematic and continuous anti-inflammatory therapy. Inhaled corticosteroids (ICS) are the most effective class of drugs, which suppress inflammation and alleviate the symptoms of the disease [1]. Not surprisingly, ICS are recommended as the first-line therapy of asthma treatment, regardless of the type of the disease and the patients' age [2].

The safety of ICS depends on their dose, formulation and pharmacological properties. It has been accepted that in adults a safe daily dose of ICS, which does not increase the risk of significant side effects, is equivalent to $400 \mu \mathrm{g}$ of budesonide [2]. Therefore, while the use of low to moderate doses of ICS is not associated with a substantial risk of systemic side effects, such a risk becomes significant in patients requiring high doses. Several attempts have been made to minimize the dose of ICS without losing their efficacy. The introduction of hydrofluoroalkanes (HFAs), as carrier-solvents, and socalled "extra-fine" preparations containing a high proportion of respirable fraction of particles in metered dose inhalers (MDI) improved significantly ICS deposition in the lungs [3-5]. This also resulted in the reduction of local side effects, such as oral candidiasis and dysphonia, however, did not eliminate completely their systemic impact. Currently used ICS differ in this respect, especially in relation to the suppression of adrenal glands. The effect of hypothalamic-pituitary-adrenal (HPA)-axis suppression has been demonstrated for the majority of currently used ICS [6-13]. Interestingly, it has been shown

Address for correspondence: Jerzy Marczak MD, PhD, Department of Pneumonology and Allergy, Medical University of Lodz, 22 Kopcinskiego St, 90-153 Lodz, Poland, phone: +48 4267821 29, +48 4267766 99, fax: +48 426782129 ,

e-mail: jerzy.marczak@umed.lodz.pl

Received: 24.06.2013, accepted: 20.08.2013. 
that the degree of HPA suppression is different for the same inhaled corticosteroid and depends on its formulation [14]. Fluticasone (FP) administered with a dry power inhaler (DPI) did not differ from placebo in this respect, while the same dose of FP in chlorofluorocarbon (CFC) formulation in MDI significantly decreased the concentration of plasma cortisol [14]. These observations indicate that the systemic side effect depends more on the dose deposited in the lung than the labeled dose. When compared to other ICS, ciclesonide (CIC) seems to be the closest to the "ideal inhaled steroid". The CIC is a product of a modern philosophy in drug manufacturing, which was designed as a prodrug with high lung deposition (up to $52 \%$ ), high relative-glucocorticoid-receptor-binding affinity $(R R A=1200)$ and very high plasma protein binding (approximately 99\%) of its active metabolite (desisobutyryl-ciclesonide, des-CIC) [15]. Furthermore, CIC is close to an ideal due to its low risk of local and systemic side-effects, low bioavailability, extensive first-pass metabolism and wide therapeutic dose range. It has been proved that $\mathrm{CIC}$ both in moderate $(320 \mu \mathrm{g} /$ day $)$ [15] and high doses

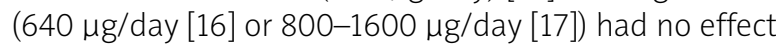
on HPA-axis suppression. Although $640 \mu \mathrm{g} /$ day is the highest approved dose for $\mathrm{CIC}$, sometimes significantly higher doses of $\mathrm{CIC}$ (reaching 1600-2400 $\mu \mathrm{g}$ /day) are used in clinical practice. However, the effect of such a therapy on adrenal suppression has been poorly investigated.

\section{Material and methods}

\section{Study design}

This was an open-label, one-center study involving 5 volunteers. All participants signed informed consent and the study was approved by the Ethical Committee of the Medical University in Lodz. All patients reported at least a 20-year history of asthma defined as uncontrolled and difficult to treat, as specified in asthma management guidelines [2]. At baseline, the treatment (apart from other medications) included prednisone in the mean dose of $15 \mathrm{mg} /$ day taken continuously and inhaled corticosteroids in high doses, equivalent to 800-1600 $\mu$ g of budesonide. The patients' baseline characteristics are presented in Table 1. The exclusion criteria comprised well-controlled asthma, known or suspected hypersensitivity to CIC, active malignancies, inability to understand procedures associated with the study or to perform spirometry or to inhale CIC properly, active tuberculosis, asthma exacerbation 4 weeks preceding the study, necessity of taking systemic corticosteroids due to the exacerbation of asthma during the study or due to diseases other than asthma.

The medical history was taken and physical examination was performed in all patients at baseline. Asthma control was assessed by means of the asthma control test questionnaire and spirometry was performed in all participants. The blood sample for ACTH and cortisol levels was taken in the morning before 8:00 am. After the assessment of inclusion and exclusion criteria, currently used ICS were withdrawn and the patients started treatment with inhaled $\mathrm{CIC}$. It was an add-on treatment option, with a daily dose ranging 1600-2400 $\mu \mathrm{g} /$ day (from 5 puffs twice a day to 5 puffs 3 times a day). The patients continued treatment with inhaled $\mathrm{CIC}$ and with previously used medicaments whereas the dose of prednisone was gradually decreased according to an individualized plan, which was designated to achieve and maintain asthma control. Furthermore, physical examination,

Table 1. Patients' characteristics

\begin{tabular}{|c|c|c|c|c|c|}
\hline \multirow[t]{2}{*}{ Parameter } & \multicolumn{5}{|c|}{ Patients } \\
\hline & EP & LW & ZB & KS & $\mathrm{TZ}$ \\
\hline Age [years] & 61 & 47 & 58 & 34 & 42 \\
\hline Sex & $\mathrm{F}$ & $\mathrm{F}$ & $M$ & $\mathrm{~F}$ & M \\
\hline Duration of asthma & 30 & 30 & 35 & 30 & 22 \\
\hline Allergy & $\begin{array}{l}\text { D.pt, D.far, flour, } \\
\text { grass, birch }\end{array}$ & D.pt, D.far, cat & None & D.pt, D.far & D. pt, D.far, grass \\
\hline Steroids bursts/year & 4 & 7 & Constantly & 5 & 6 \\
\hline $\begin{array}{l}\text { Dose of prednisone } \\
\text { at baseline }\end{array}$ & 30 & 20 & 10 & 10 & 5 \\
\hline $\begin{array}{l}\text { Recommended dose } \\
\text { of ciclesonide }[\mu \mathrm{g} / \mathrm{day}]\end{array}$ & 2400 & 2400 & 1600 & 1600 & 1600 \\
\hline $\begin{array}{l}\text { Asthma treatment } \\
\text { (daily dose) }\end{array}$ & 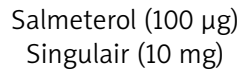 & $\begin{array}{l}\text { Formoterol }(18 \mu \mathrm{g}) \\
\text { Singulair }(10 \mathrm{mg})\end{array}$ & $\begin{array}{c}\text { Formoterol }(18 \mu g) \\
\text { Singulair (10 mg) }\end{array}$ & $\begin{array}{c}\text { Formoterol }(18 \mu g) \\
\text { Singulair }(10 \mathrm{mg})\end{array}$ & $\begin{array}{c}\text { Formoterol }(18 \mu \mathrm{g}) \\
\text { Singulair }(10 \mathrm{mg})\end{array}$ \\
\hline Smoking history & No & No & Yes & No & No \\
\hline Comorbidities & $\begin{array}{l}\text { Atopic dermatitis, } \\
\text { allergic rhinitis, } \\
\text { diabetes mellitus }\end{array}$ & Allergic rhinitis & & Allergic rhinitis & Allergic rhinitis \\
\hline
\end{tabular}

D.pt-Dermatophagoides pteronyssinus, D.far - Dermatophagoides farinae, COPD - chronic obstructive pulmonary disease 
ACT and spirometry were performed on the $7^{\text {th }}, 28^{\text {th }}, 56^{\text {th }}$ and $70^{\text {th }}$ day of treatment whereas blood sampling for ACTH and cortisol levels was performed in the morning on the $28^{\text {th }}$ and $56^{\text {th }}$ day of treatment with $\mathrm{CIC}$.

\section{Spirometry}

Spirometry was performed with a daily calibrated spirometer (Lung Test 1000, MES Dymek, Dabrowski SA, Krakow, Poland), according to the ERS/ATS guideline [18]. The values of force expiratory volume in $1 \mathrm{~s}\left(\mathrm{FEV}_{1}\right)$ and forced expiratory volume were expressed in liters and as the percentage of predicted values.

\section{Asthma control test}

The Asthma Control Test (ACT) was used for the assessment of the disease control level, according to the recommendations [19]. The maximum score was 25 and asthma was considered as not well controlled if the result of ACT was $<19$ points.

\section{Determination of adrenocorticotropic hormone and cortisol levels in the serum}

Serum cortisol and ACTH levels were measured with standardized, commercially available tests (Vitros Cortisol Reagent Pack by Ortho-Clinical Diagnostics, Cardiff, UK, and ACTH Test for Siemens Medical IMMULTE 1000) by Siemens Healthcare Diagnostics (Inc., Tarrytown, NY, USA). Normal plasma ACTH concentration is $10-60 \mathrm{ng} / \mathrm{l}$

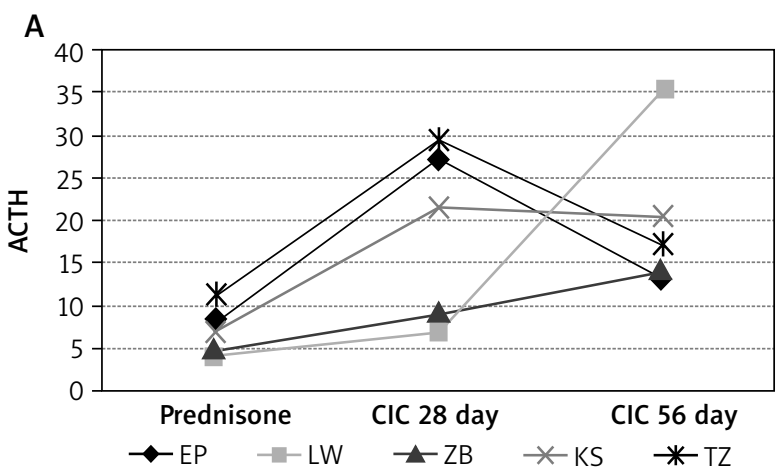

whereas for cortisol normal concentration at 8:00 is 138$635 \mathrm{nmol} / \mathrm{l}$. The sensitivity of these assays is $3 \mathrm{nmol} / \mathrm{l}$.

\section{Administration of ciclesonide}

Commercially available $\mathrm{CIC}$ was prescribed in the dose 160 Mg/puff (Alvesco, Nycomed, Zurich, Switzerland) and was inhaled at a daily dose from 1600 mg (5 puffs twice a day) to $2400 \mu \mathrm{g}$ (5 puffs three times a day) (Table 1).

All patients were instructed how to inhale the medication properly and the method of $\mathrm{CIC}$ inhalation was assessed by physicians at each visit during the study.

\section{Results}

The evaluation was conducted in 5 patients (3 women and 2 men) with poorly controlled asthma who were treated in an outpatient clinic of our hospital (Table 1). The discontinuation of prednisone was achieved after 3 days in patient TZ, 6 days in ZB and KS, and 10 days in EP and LW patients.

Morning baseline ACTH levels were below the lower limit of normal values in 4 patients (Figure $1 \mathrm{~A}$, prednisone), whereas the cortisol concentration was below the lower range in 3 subjects and in 2 patients was normal, however close to the lower limit of its morning concentration in blood (Figure $1 \mathrm{~B}$, prednisone).

The ACTH levels were normalized in 3 patients after 4 weeks and in all subjects after 56 days of CIC intake. Cortisol levels were normalized in 4 patients after 4 weeks of treatment $\left(28^{\text {th }}\right.$ day). After another 4 weeks, in the

B

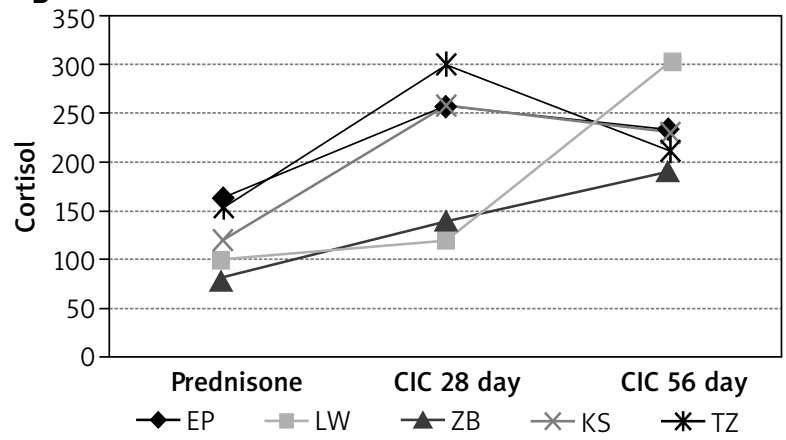

Figure 1. Serum levels of ACTH (A) and cortisol (B)

Table 2. Plasma concentrations of adrenocorticotropic hormone (ACTH) and cortisol, force expiratory volume in $1 \mathrm{~s}$ $\left(\mathrm{FEV}_{1}\right)$ and $\mathrm{ACT}$ score

\begin{tabular}{lccccc}
\hline Parameter & Baseline & 7 day & 28 day & 56 day & 70 day \\
\hline ACTH $[\mathrm{nmol} / \mathrm{l}]$ & $7.08 \pm 2.63$ & - & $18.88 \pm 10.3$ & $20.02 \pm 9.02$ & - \\
\hline Cortisol $[\mathrm{nmol} / \mathrm{l}]$ & $123.6 \pm 34.8$ & - & $215.0 \pm 79.8$ & $233.8 \pm 42.0$ & - \\
\hline FEV $[\mathrm{l}]$ & $1.78 \pm 0.39$ & $1.9 \pm 0.57$ & $2.12 \pm 0.66$ & $2.19 \pm 0.62$ & $2.23 \pm 0.69$ \\
\hline ACT $[\mathrm{pt}]$ & $9.4 \pm 0.89$ & - & $18.4 \pm 3.78$ & $19.8 \pm 2.77$ \\
\hline
\end{tabular}




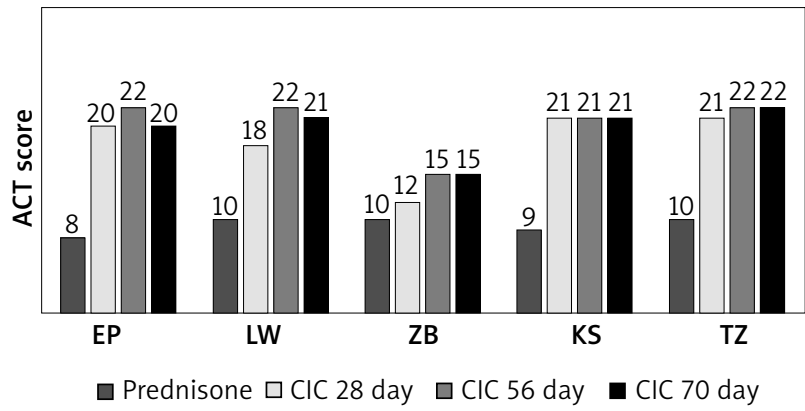

Figure 2. ACT score in patients treated with ciclesonide

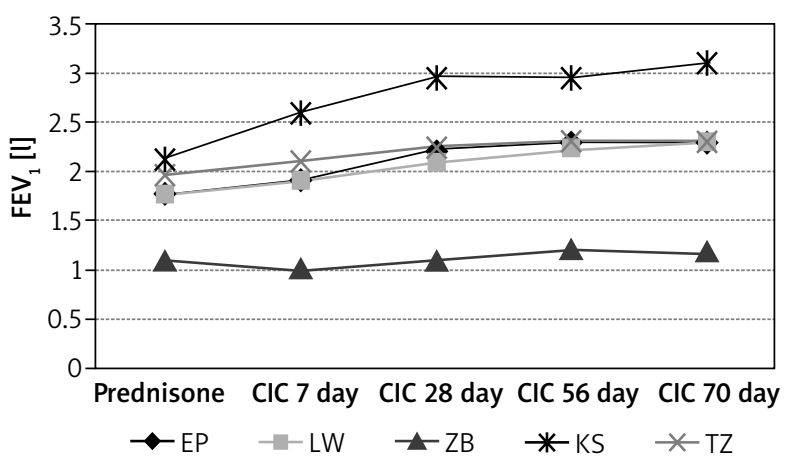

Figure 3. Force expiratory volume in $1 \mathrm{~s}\left(\mathrm{FEV}_{1}\right)$ in patients treated with prednisone (baseline) and ciclesonide (CIC)

shown that CIC at a dose of 1600-2400 $\mu \mathrm{g}$ /day improved asthma control, expressed by ACT scores, improved $\mathrm{FEV}_{1}$ in the majority of patients as well as normalized the ACTH and cortisol levels in all patients. Previous observations indicated the absence of systemic effects of $\mathrm{CIC}$ at doses of up to $640-1280 \mu \mathrm{g} /$ day [15]. The idea of using higher doses of $\mathrm{CIC}$ seems to be very promising. Szefler et al. reported significantly reduced serum cortisol AUC 0-24 h after $1780 \mu \mathrm{g} /$ day of fluticasone in contrast to an unchanged level at a dose of $1280 \mu \mathrm{g} /$ day of CIC [30]. Heller et al. [31] observed the reversal of adrenal suppression caused by high doses of inhaled fluticasone in 4 children with asthma treated with high doses of $\mathrm{CIC}$. These observations reinforce the strength of arguments that $\mathrm{CIC}$ should be designated for severe asthma requiring high doses of ICS.

In our study all patients were able to discontinue oral corticosteroids permanently (OCS) during the whole 10 weeks of observation. Bateman revealed a similar effect using a dose of 640-1280 $\mu$ g in a group of $141 \mathrm{pa}-$ tients with steroid-dependent asthma yielding a 30\% rate of permanent discontinuation of OCS [32]. It is worth stressing that the improvement of asthma control was achieved in all patients, regardless of the phenotype of the disease, both with a history of atopy, poor reversibility (TZ) or smoking history (ZB). The lack of noticeable improvement of $\mathrm{FEV}_{1}$ in $\mathrm{ZB}$ patient may result from smoking reported by this patient and probably more pronounced COPD phenotype.

In the assessment of HPA axis we did not use the method recommended by the Asthma Clinical Research Network based on the analysis of an overnight in-laboratory evaluation of plasma cortisol every hour or every 2 h. In our study, we applied a simple single measurement of morning cortisol, which may be beneficial due to the practical character of the study [13].

An interesting fact concerning our study was that the beneficial effect of prednisone withdrawal was observed especially in patient TZ, who was taking a minimal dose of prednisone ( $5 \mathrm{mg} /$ day) at baseline. This phenomenon is difficult to explain, but proves that the use of even 
small repeated doses of OCS leads to an impaired HPA axis, which is reversible after switching to CIC [33].

\section{Conclusions}

Oral corticosteroids are currently used as the last-line therapy of difficult asthma, if previously recommended steps of treatment are not effective enough to control the disease, but may produce substantial systemic side effects and suppress the HPA axis. Very high doses of inhaled $\mathrm{CIC}$ do not produce significant side effects and may improve the lung function and disease control. Switching from $\mathrm{OC}$ to very high doses of $\mathrm{CIC}$ may also be beneficial in reversing the adrenal suppression caused by OC. Therefore, it is worth continuing studies which would state if very high doses of $\mathrm{CIC}$ could be regarded as a treatment option for patients with difficult asthma, who are considered as candidates for OC.

\section{Acknowledgments}

The study was done in the Department of Pneumonology and Allergy, Medical University of Lodz, Poland. The study was self funded (Medical University of Lodz) and was approved by the ethics committee of the Medical University in Lodz.

\section{Conflict of interest}

All authors declare no conflict of interest.

\section{References}

1. Jeffery PK, Godfrey RW, Adelroth E, et al. Johansson SA. Effects of treatment on airway inflammation and thickening of basement membrane reticular collagen in asthma. A quantitative light and electron microscopic study. Am Rev Respir Dis 1992; 145: 890-9.

2. Global Strategy for Asthma Management and Prevention. Global Initiative for Asthma (GINA) 2012. Available from: http://www.ginasthma.org/

3. Barnes N, Price D, Colice G, et al. Asthma control with extrafine-particle hydrofluoroalkane-beclometasone vs. large particle chlorofluorocarbon-beclometasone: a real-world observational study. Clin Exp Allergy 2011; 41: 1521-32.

4. Singh D, Tutuncu A, Lohr I, et al. Budesonide administered using chlorofluorocarbon and hydrofluoroalkane pressurized metered-dose inhalers: pharmacokinetics, pharmacodynamics and clinical equivalence. Int J Clin Pharmacol Ther 2007; 45: 485-95.

5. Menzies D, Nair A, Hopkinson P, et al. Differential anti-inflammatory effects of large and small particle size inhaled corticosteroids in asthma. Allergy 2007; 62: 661-7.

6. Brus R. Effects of high-dose inhaled corticosteroids on plasma cortisol concentrations in healthy adults. Arch Intern Med 1999; 159: 1903-8.

7. Lundback B, Alexander M, Day J, et al. Evaluation of fluticasone propionate administered either as dry powder via a Diskhaler inhaler or pressurized inhaler and compared with beclomethasone dipropionate administered by pressurized inhaler. Respir Med 1993; 87: 604-20.

8. Nikolaizik WH, Marchant JL, Preece MA, et al. Nocturnal cortisol secretion in healthy adults before and after inhalation of budesonide. Am J Respir Crit Care Med 1996; 153: 97-101.

9. McCubbin MM, Milavetz G, Grandgeorge S, et al. A bioassay for typical and systemic effect of three inhaled corticosteroids. Clin Pharmacol Ther 1995; 57: 455-60.

10. Clark DJ, Grove A, Cargill RI, et al. Comparative adrenal suppression with inhaled budesonide and fluticasone propionate in adult asthmatics. Thorax 1996; 51: 262-6.

11. Lonnebo A, Grahnen A, Jansson B, et al. An assessment of the systemic effects of single and repeated doses of inhaled fluticasone propionate and inhaled budesonide in healthy volunteers. Eur J Clin Pharm 1996; 49: 459-63.

12. Boorsma M, Anderson N, Larsson P, et al. Assessment of the relative systemic potency of inhaled fluticasone and budesonide. Eur Respir J 1996; 9: 1427-32.

13. Altman LC, Findlay SR, Lopez M, et al. Adrenal function in adult asthmatics during long-term daily treatment with $800,1,200$, and 1,600 micrograms triamcinolone acetonide. Chest 1992; 101: 1250-6.

14. Martin RJ, Szefler SJ, Chinchilli VM, et al. Systemic effect comparisons of six inhaled corticosteroid preparations. Am J Respir Crit Care Med 2002; 165: 1377-83.

15. Nave R. Clinical pharmacokinetic and pharmacodynamic profile of inhaled ciclesonide. Clin Pharmacokinet 2009; 48: 243-52.

16. Derom E, Louis R, Tiesler C, et al. Effects of ciclesonide and fluticasone on cortisol secretion in patients with persistent asthma. Eur Respir J 2009; 33: 1277-86.

17. van den Berge M, Arshad SH, Ind PW, et al. Similar efficacy of ciclesonide versus prednisolone to treat asthma worsening after steroid tapering. Respir Med 2009; 103: 1216-23.

18. Lipworth BJ, Kaliner MA, LaForce CF, et al. Effect of ciclesonide and fluticasone on hypothalamic-pituitary-adrenal axis function in adults with mild-to-moderate persistent asthma. Ann Allergy Asthma Immunol 2005; 94: 465-72.

19. Miller MR, Crapo R, Hankinson J, et al. General considerations for lung function testing. Eur Respir J 2005; 26: 153-61.

20. Halbert RJ, Tinkelman DG, Globe DR, et al. Measuring asthma control is the first step to patient management: a literature review. J Asthma 2009; 46: 659-64.

21. Milinarsky TA, Fischer GS, Giadrosich RV, et al. High doses of inhaled budesonide and adrenal function in children with severe asthma. Rev Med Chil 2006; 134: 60-4.

22. Schuh S, Dick PT, Stephens D, et al. High-dose inhaled fluticasone does not replace oral prednisolone in children with mild to moderate acute asthma. Pediatrics 2006; 118: 644-50.

23. Lee DK, Fardon TC, Bates CE, et al. Airway and systemic effects of hydrofluoroalkane formulations of high-dose ciclesonide and fluticasone in moderate persistent asthma. Chest 2005; 127: 851-60.

24. Hodyl NA, Stark MJ, Osei-Kumah A, et al. Fetal glucocorticoid-regulated pathways are not affected by inhaled corticosteroid use for asthma during pregnancy. Am J Respir Crit Care Med 2011; 183: 716-22.

25. Blais L, Beauchesne MF, Lemière C, et al. High doses of inhaled corticosteroids during the first trimester of pregnancy and congenital malformations. J Allergy Clin Immunol 2009; 124: 1229-34.

26. Weinstein SF, Corren J, Murphy K, et al. Twelve-week efficacy and safety study of mometasone furoate/formoterol 200/10 microg and 400/10 microg combination treatments 
in patients with persistent asthma previously receiving high-dose inhaled corticosteroids. Allergy Asthma Proc 2010; 31: 280-9.

27. Pauwels RA, Löfdahl CG, Postma DS, et al. Additive effects of inhaled formoterol and budesonide in reducing asthma exacerbations: a one-year, controlled study. N Engl J Med 1998; 337: 1405-11.

28. Adachi M, Ishihara K, Inoue $\mathrm{H}$, et al. Efficacy and safety of once-daily inhaled ciclesonide in adults with mild to moderate asthma: a double blind, placebo-controlled study. Respirology 2007; 12: 566-72.

29. Langdon CG, Adler M, Mehra S, et al. Once-daily ciclesonide 80 or 320 microg for 12 weeks is safe and effective in patients with persistent asthma. Respir Med 2005; 99: 1275-85.

30. Szefler S, Rohatagi S, Williams J, et al. Ciclesonide, a novel inhaled steroid, does not affect hypothalamic-pituitaryadrenal axis function in patients with moderate-to-severe persistent asthma. Chest 2005; 128: 1104-14.

31. Heller MK, Laks J, Kovesi TA, et al. Reversal of adrenal suppression with ciclesonide. J Asthma 2010; 47: 337-9.

32. Bateman E, Karpel J, Casale T, et al. Ciclesonide reduces the need for oral steroid use in adult patients with severe, persistent asthma. Chest 2006; 129: 1176-87.

33. Agertoft L, Pedersen S. Lower-leg growth rates in children with asthma during treatment with ciclesonide and fluticasone propionate. Pediatr Allerg Immunol 2010; 21: 199-205. 